\title{
Rapid Migration of Radionuclides Leaked from High-Level Waste Tanks: A Study of Salinity Gradients, Wetted Path Geometry, and Water Vapor Transport
}

(Project Number: 65410)

\section{Principal Investigator}

Anderson L. Ward

Pacific Northwest National Laboratory

P.O. 999, MSIN K9-33

Richland, WA 99352

(360) 574-5874 (phone)

(509) 372-6089 (fax)

andy.ward@pnl.gov

\section{Co-Investigators}

Glendon Gee

Pacific Northwest National Laboratory

P.O. 999, MSIN K9-33,

Richland, WA 99352

(360) 574-5874 (phone)

(360) 571-5874 (fax)

glendon.gee@pnl.gov

John Selker

Department of Bioresource Engineering

Oregon State University

Corvallis, OR 97331-3906

(541) 737-6304 (phone)

(541) 737-2082 (fax)

selkerj@engr.orst.edu

Scott Tyler

Desert Research Institute

755 E. Flamingo Rd.

Las Vegas, NV 89119-7363

(775) 673-7391 (phone)

(775) 673-7363 (fax)

scott@dri.edu 


\section{Problem Statement}

Previous attempts to predict field-scale contaminant transport through the vadose zone at the Hanford Site have often neglected driving forces and mechanisms that are known to contribute to preferential flow. It is now clear that a basic understanding of the behavior of dense high ionicstrength fluids through the vadose zone is critical to the evaluation of remediation options and for predicting future migration. Preferential flow has been shown to be capable of producing erratic transport patterns and can cause contaminants to bypass much of the unsaturated soil matrix. These processes lead to fast transport of contaminants to underlying groundwater and the resulting lack of interchange between the main soil matrix and the fast pathways reduces the potential for natural attenuation. Our hypothesis is that elevated surface tension and density of leaked tank wastes will lead to the formation of narrow fingers of infiltration, reducing lateral contaminant spreading, and increasing the depth of penetration. The extent and persistence of these fingers will be influenced by natural precipitation as well as water migrating into the saline zone in response to the osmotic potential gradient.

\section{Research Objectives}

This study combines laboratory, field, and numerical experiments with the following objectives: to investigate the effect of elevated surface tension, density, and viscosity of highly saline fluids on soil water-retention properties, wetting front instability, the formation and persistence of fingers, and contaminant mobility to investigate the conditions under which osmotically driven vapor flux is operative and quantify its impact on plume transport to develop and incorporate a theory describing these processes into an existing DOE-developed, numerical simulator to allow prediction of contaminant migration at realistic spatial and temporal scales. The product will be a tool that DOE can use to perform more realistic analyses to predict fate and transport of high ionic-strength contaminants, evaluate different tank waste retrieval strategies and their impact on the vadose zone, and assess the associated health risks.

\section{Research Progress}

The report summarizes work after 16 months of a three-year project that started in October 1998. As of February 2000, under the controlled laboratory experiments tasks, we have successfully demonstrated the formation of fingers during the infiltration of concentrated tank waste simulants. We have been successful in demonstrating the utility of x-ray computed tomography (XRCT) for monitoring 3-D finger evolution in Hanford sediments.

Studies in 2-D light chambers have also produced good results so far. Studies were performed with pure 5-M NaNO 3 and with $\mathrm{NaNO}_{3}+2 \%$ methanol by volume designed to maintain the density and viscosity effects while reducing the surface tension to a value similar to water. A variety of well-characterized silica sands are being used in this study to allow identification of the dominant mechanisms. Figure 1 shows the results at four different times for the application of three 5-mL plumes in 30/40 Accusand ${ }^{\circledR}$. The plumes consisted of $5 \mathrm{M} \mathrm{NaNO}_{3}$, 


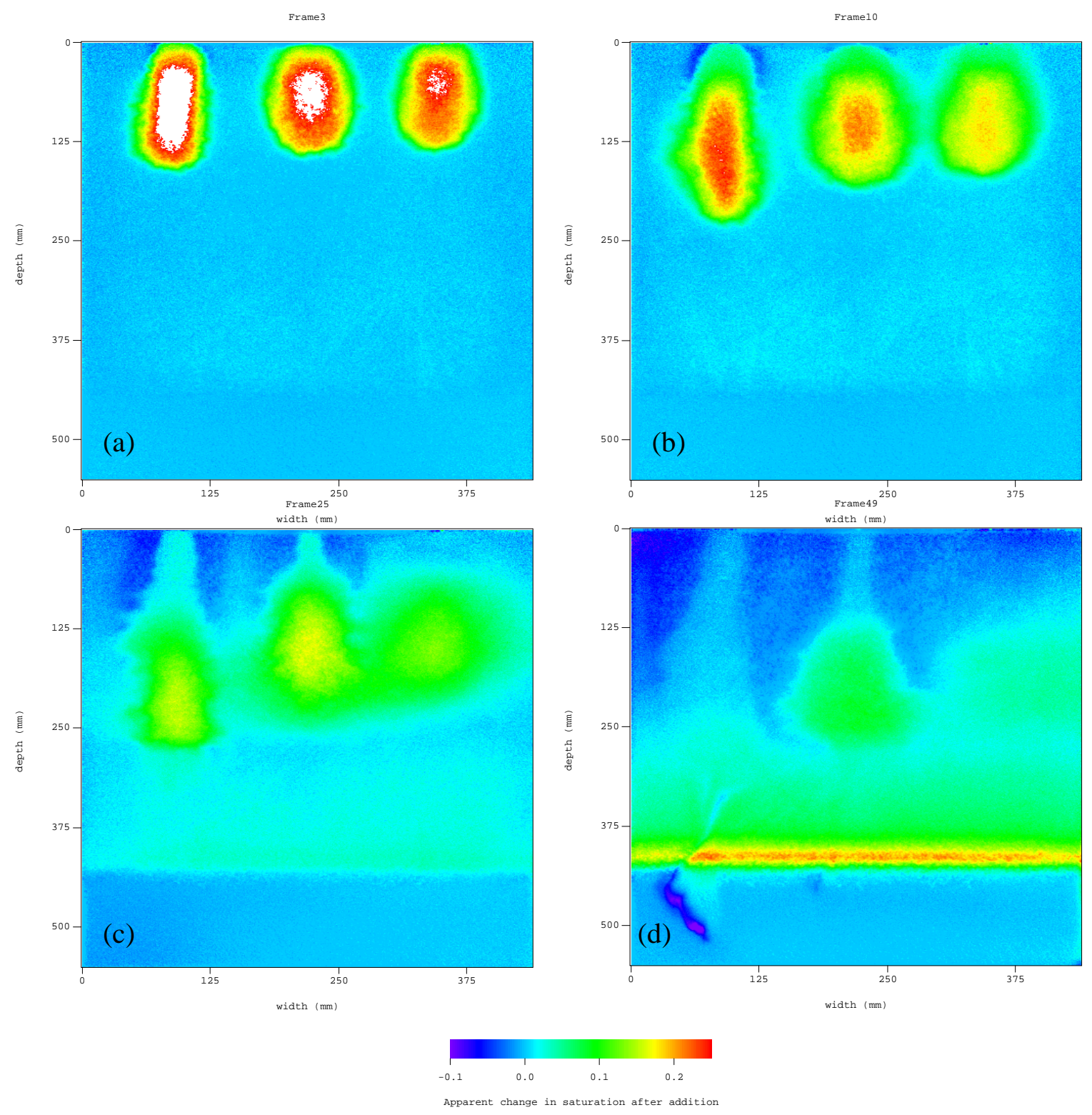

Figure 1. Infiltration Patterns of 5-mL Pulse of Concentrated Solutions Into 30/40 Accusand; (a) After $0.5 \mathrm{Hr}$ of Infiltration, (b) After $1.6 \mathrm{Hr}$ of Infiltration, (c) After $10 \mathrm{Hr}$, and (d) After $64 \mathrm{Hr}$. The solutions applied were (from left to right): $5 \mathrm{M} \mathrm{NaNO}_{3}, 5 \mathrm{M}$ $\mathrm{NaNO}_{3}+2 \%$ methanol by volume, and Nanopure ${ }^{\circledR}$ water.

$5 \mathrm{M} \mathrm{NaNO}_{3}+2 \%$ methanol by volume, and distilled water (from left to right). The salt plume (left) clearly infiltrated faster than the other two plumes, despite the similarity in densities between the left two plumes. It appears that the high surface tension of the salt plume is responsible for the higher velocity. The effect of the osmotic gradient is also clear. The darker blue regions on the figure indicate water saturation below levels present before the addition of the plumes (see color table at the bottom of the figure). Desaturation of areas adjacent to both 
salt fingers continues throughout the experiment. In addition, at a later time $(\sim 10 \mathrm{hr})$, water from the right plume was being drawn into the adjacent salt plume. This is likely in response to the osmotic gradient between the two plumes. Another interesting phenomenon observed in the later stages of the infiltration experiment $(\sim 60 \mathrm{hr})$ is the mobilization of colloids. Soon after the salt plume reached the capillary fringe (375-400 $\mathrm{mm}$ depth) reddish "tail," apparently colloidal materials, developed and moved down toward the bottom of the chamber (density driven). The tail was also observed below the salt plume with $2 \%$ methanol but was less pronounced.

Under the modeling task, we have been successful in developing and implementing thermodynamic based model of surface tension as a function of ionic composition. The model uses the Pitzer equations to predict osmotic coefficients from which surface tensions can be derived for concentrated aqueous solutions. The resulting model has been used to scale the hysteretic water retention and hydraulic conductivity relations to predict the effects of tank waste on soil hydraulic properties and infiltration processes. As the concentration of salt in the fluid increases, the surface tension increases and wettability decreases, causing an arrest of spontaneous imbibition. This condition is known to cause finger formation in water-repellant soils. Another important achievement has be the start of work on the incorporation of adaptive gridding techniques into the STOMP simulator to allow tracking of fingers from their formation at the local scale through their development over larger spatial scales. The approach is based on static local uniform grid refinement method that integrates on nested sequences of local uniformly refined Cartesian grids. This will overcome current limitations on our ability to track fingers at realistic scales after their formation.

\section{Planned Activities}

During the remainder of this fiscal year, laboratory experiments will continue to measure the effect of ionic composition on fluid properties and to characterize the effect of concentrated electrolyte solutions of water retention and hydraulic conductivity relationships. These results will be used to validate the theory developed to describe the effects. Work is ongoing to collect laboratory data to verify the predicted surface tensions and observed changes in constitutive properties. An apparent difference in effect on the imbibition and desorption curves will be explored in the coming months. Tank waste simulants will be used in intermediate-scale flow cells packed with Hanford sediments to observe the infiltration of tank waste simulants under controlled conditions and identify the conditions under which fingers form and factors affecting their persistence. The light chamber studies will continue with some emphasis on identifying the conditions under which colloids are mobilized and how they impact transport to the water table. Another field experiment to observe in situ infiltration and transport behavior in Hanford formation soils will be conducted this summer, while monitoring of the long-term plume migration experiment continues. These studies will provide data for validation of model predictions at the field scale. 